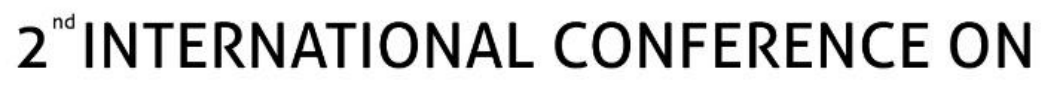 FUTURE OF TEACHING \& EDUCATION
}

Munich,Germany

6 - 8 December,2019

\section{Digitalized Out-of-Class Speaking Practice}

\author{
Meriç Akkaya-Önal \\ Anadolu University School of Foreign Languages
}

\begin{abstract}
Learning English in an EFL environment presents various challenges for learners, among which speaking emerges as one of the most demanding aspects. Although learners have been raised in a digitalized era, using computer-mediated communication as a part of language learning is not their forte. Therefore, this study aims to explore whether students perceive that the computermediated communicative (CMC) out-of-class speaking activities support the development of their oral speaking skills, and whether these out-of-class speaking activities contributed to building their level of confidence with respect to using the target structures and vocabulary in the classroom.

The research was conducted at a public university in Turkey with a number of 6 participants, who were chosen among upper-intermediate level students on voluntary basis. The data for this research were collected through five different PPT slides, interviews at the end of each PPT and a final interview, which was conducted at the end of the study. The PPT slides, prepared by the researcher and checked by two colleagues, included target grammar and lexical structures which took place in their coursebook along with voice and video recordings. The participants were interviewed right after each PPT lesson was completed, and a final interview was conducted at the very end of the study.

The qualitative analysis from the interviews yielded that participants were quite positive towards these digitalized out-of-class speaking activities since they contributed them both pedagogically and academically.
\end{abstract}

Keywords: Computer-mediated communication (CMC), out-of-class speaking 